\title{
Política social e democracia: reflexões sobre o legado da seguridade social
}

* Escola Brasileira de Administraçāo Pública da Fundação Getúlio Vargas e Escola Nacional de Saúde Pública FIOCRUZ - RJ

\section{Sonia Maria Fleury Teixeira ${ }^{*}$}

$O$ artigo procura abordar o campo das politicas sociais a partir do desenvolvimento da cidadania, compreendida como a pauta de direitos e deveres que se estabelece entre aqueles aos quais se atribui a condição de cidadão e seu Estado. Neste sentido, a autora procura demonstrar que as politicas sociais são intervenções estatais condicionadas pela demanda existente e pelo contex to histórico no qual emergem. Desta forma, podem assumir diferentes modalidades, como a assistência social, o seguro social e o Estado do Bem-Estar Social. O predominio de uma ou outra destas modalidades em cada sociedade, configurou distintos padrões de intervenção estatal no trato das questões sociais nos paises mais desenvolvidos, que se diferenciam em função da maior ou menor justiça $e$ eqüidade dos sistemas prestadores de serviços sociais.

Na América Latina, o desenvolvimento das politicas sociais enfrentou problemáticas especificas que são analisadas pela autora.

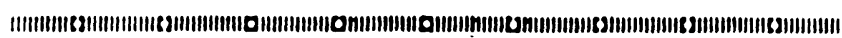

\section{POLITICA SOCIAL E CIDADANIAS}

O campo das políticas sociais, embora carecendo de um maior rigor conceitual, recebe sua melhor definição quando tratado sob a égide do conceito de cidadania. Assim, as políticas sociais tratariam dos planos, programas e medidas necessários ao reconhecimento, implementação, exercício e gozo dos direitos sociais reconhecidos em uma dada sociedade como incluídos na condição de cidadania, gerando uma pauta de direitos e deveres entre aqueles aos quais se atribui a condição de cidadãos e seu Estado. Esta relação ju rídica de reciprocidade inclui, além dos direitos sociais, os direitos civis e políticos, sendo que, embora cada um destes elementos tenha tido um curso histórico distinto no seu desenvolvimento, atualmente estão entrelaçados e indissociavelmente vinculados à noção de cidadania ${ }^{7}$.
Recebido para publicação em $2 / 10 / 85$ 
Com relação às medidas de proteção social que o Estado implementa através das políticas sociais, há que se reconhe. cer sua heterogeneidade, já que elas não têm necessariamente o mesmo significado político e jurídico no que diz respeito ao exercício dos direitos sociais. As diferentes formas assumidas pela proteção podem ser separadas a partir do contexto social e político no qual historicamente tiveram origem, desde o surgimento do Estado Moderno. Assim, poderíamos distinguir ${ }^{21}$ três modalidades principais: Assistência Social, Seguro Social e o Estado do Bem-Estar Social. Para além de sua origem em momentos distintos, trata-se de assinalar que tais modalidades foram marcadas por estes contextos, diferenciando-se também ao nível das relações políticas, ju rídicas e institucionais.

As primeiras medidas de proteção social tiveram origem em um contexto rigidamente liberal, no qual se negava a necessidade de intervenção estatal nas questões de natureza social, sob a alegação da eficácia do mercado no trato dos problemas sociais emergentes. Malgrado a bela construção teórico-ideológica do liberalismo, o mercado mostrou-se incapaz de dar conta dos problemas que ele mesmo gerava, especialmente na esfera da reprodução humana, exigindo assim a crescente intervenção do Estado, tanto na esfera da produção regulando as relações de trabalho, quanto na esfera da reprodução, através de medidas de proteção social.

As políticas sociais que tiveram origem neste contexto são conhecidas sob a designação de Assistência Social e incluíam o reconhecimento de uma necessidade, e alguma proposta de aliviá-la. Caracterizam se por assumir que esta situação de necessidade decorre de um problema de caráter do necessitado, razão pela qual a assistência é provida em condições que tentam parcialmente compensar falhas passadas e prevenir contra falhas futuras.

A natureza compensatória e punitiva destas medidas evidencia-se, por exemplo, na perda de outros direitos inerentes à condição de cidadania (no caso dos menores protegidos pelo Estado), ou em restrições de ordem simbólica tais como rituais de degradação, atestados de miséria, etc, a que são submetidas as familias carentes. Esta condição política de cidadania invertida, em que o indivíduo entra em relação com o Estado no momento em que se reconhece como um não-cidadão, tem como atributos jurídicos e institucionais, respectivamente, a ausência de uma relação formalizada de direito ao benefício, o que se reflete na instabilidade das políticas assistenciais, além de uma base institucional que reproduz um modelo de voluntariado das organizações de caridade, mesmo quando exercidas em instituições estatais. 
A segunda forma assumida pela proteção social já é fruto de um contexto social no qual a classe operária é reconhecida como ator qualificado na ordem política e econômica. O Seguro Social tem como característica destinar-se à cobertura da população assalariada com a qual se estabelece uma relação jurídica do tipo contratual: os benefícios são, em regra, proporcionais à contribuição efetuada, não guardando relação imediata com as necessidades do beneficiário. A participação tende a ser compulsória e, embora restrita a uma parcela da população, é uma relação de direito social estabelecida com base em um contrato. Trata-se, neste caso, da cidadania regulada ${ }^{19}$ pela condição de exercício de uma ocupação oficialmente reconhecida, o que the garante a assinatura da carteira de trabalho.

As instituições responsáveis pela prestação dos serviços e benefícios tendem a ser financiadas com base na contribuição salarial, ademais de aportes específicos do Estado, e submetem-se a uma lógica de capitalização de suas reservas.

Essa forma de proteção envolve questões de eqüidade, justiça social e redistribuição de renda entre a população beneficiária. Por outro lado, perpetua a iniqüidade do sistema produtivo, ao excluir da proteção exatamente os grupos mais necessitados que são os que estão à margem do mercado formal urbano de trabalho.

Finalmente, o Estado do Bem-Estar Social rompe com as concepções de proteção social com base na evidência da necessidade ou no contrato firmado, e propõe uma relação de cidadania plena, na qual o Estado está obrigado a fornecer a garantia de um minimo vital a todos os cidadãos, em relação à saúde, educação, pensão, seguro desemprego, etc. $O$ Estado do Bem-Estar Social baseia-se em uma relação de direito social inerente à condição de cidadania $\mathrm{e}$, do ponto de vista institucional, implica uma organização nacional da política social, na qual o Estado assume os ônus básicos da administração e financiamento do sistema. Trata-se de um projeto de redefinição das relações sociais em direção à redistribuição da renda $\mathrm{e}$, portanto, à eqüidade e justiça social para toda a sociedade.

Conhecidas as três modalidades de proteção social, restaria esclarecer que o fato de terem tido origem em momentos históricos sucessivos não quer dizer que este processo se assemelhe a um contínuo em uma espiral ascensional de evolução da política social rumo à cidadania plena, cada nova forma destruindo as que lhe precedem. Ao contrário, quero demonstrar a sobrevivência e concomitância das três formas descritas de política social, embora a convivência nem sempre se dê sem conflitos e contradições.

Estudiosos afirmam ${ }^{3}$ que a assistência aos pobres do século XIX permanece até hoje para o exército industrial de 
reserva, enquanto o Seguro Social cobre os trabalhadores engajados no mercado formal de trabalho, e este anacronismo é uma função de classe.

Outro ponto que parece ser crucial para a compreensão da relação entre as modalidades de política social é o predomínio do seguro social como estru tura medular de toda a política de proteção, de tal forma que se possa afirmar que as outras modalidades a ele se acoplam contraditória ou complementarmente. A comprovação desta nossa hipótese pode ser encontrada em distintas evidências em face de contextos sócio-econômicos diferentes: seja pela tendência histórica de manutenção de altos índices de emprego apresentada até recentemente pelos países desenvolvidos, fazendo com que a estrutura do seguro coincidisse com a do estado do bem-estar, seja, ainda, no caso inverso, relativo aos países de desenvolvimento dependente e retardatário, onde a única política social efetiva é a do seguro, colocando todos os que estão fora do mercado formal na condição de précidadãos.

No caso brasileiro, o que tenho demonstrado ${ }^{21}$ é a existência das três modalidades apontadas, sob a mesma base institucional previdenciária, seja pela incorporação das instituições assistenciais no sistema previdenciário, seja pela tendência à progressiva integração dos serviços de assistência médica, seja ainda pela existência de benefícios que rompem a estrutura contratual do seguro, tais como o Funrural, renda mensal vitalícia, abono, etc. Esta base institucional securitária tem-se mostrado inadequada para abranger desde medidas assistenciais até a extensão da cidadania plena, já que tais incorporações não corresponderam à redefinição dos mecanismos de financiamento e gestão do sistema. Tal inadequação evidencia-se de forma dramática nos momentos de crise financeira do sistema, nos quais volta-se sempre a defender o caráter contratual exclusivo dos benefícios previdenciários, ameaçando-se com o corte de outros benefícios que, mal ou bem, são frutos da conquista de toda a sociedade em direção a uma política social mais equânime. Ássim, já que os demais programas são sempre considerados como um hóspede indesejável, dependendo do ciclo financeiro de ascenso ou descenso da Previdencia Social, fica evidente que a superposição institucional não representou uma homogeneização da condição de cidadania, preservando o caráter político inerente a cada modalidade assinalada. Se é correto tomarmos a análise das políticas sociais a partir do eixo central da estrutura previdenciária, esta abordagem coloca duas ordens de questões que merecem ser tratadas integralmente, sem que a urgência de solucionar uma delas implique abandonar a outra à sua própria sorte. 
A primeira delas é a questão de ordem política, de redefinação da política social à luz dos princípios de eqüidade $e$ justiça social, de sorte que se busque a universalização da condição de cidadania a todos os brasileiros. Não haveria melhor momento de redefinirmos a relação de reciprocidade existente entre Estado e cidadãos, reformulando ampla e uniformemente a pauta de direitos e deveres inerentes a esta relação, senão aquele em que a sociedade brasileira se debruça em torno da reordenação das relações políticas e sociais, através da elaboração de uma Constituição que consolide o processo de transição democrática.

Está cada vez mais claro, tanto para a população brasileira quanto para seus dirigentes, que a estabilidade da transição política será dada na medida em que o novo sistema democrático incorpore efetivamente as demandas sociais.

A segunda ordem de questões envolvidas diz respeito aos mecanismos de financiamento, à autonomia institucional, modelos de gerência e a diversos outros problemas técnicoatuariais e de administração dos serviços e concessão de benefícios. Todas estas questões foram agudizadas face a crise financeira do sistema e a conjuntura recessiva que atravessa o país, já que funcionam como limites à capacidade de oferecer soluções alternativas.

Embora estes últimos problemas sejam bastante dramáticos neste momento, não se deve negligenciar a necessidade de repensar a política social em geral, com vistas a oferecer proposições à Assembléia Constituinte, limitando-nos a solucionar as falhas do sistema atual sem que este próprio sistema venha a ser objeto de transformações. Por outro lado, não se pode cair no erro oposto que consistiria em definir princípios doutrinários compatíveis com a redemocratização da sociedade, sem pesquisar os mecanismos de operacionalização desta política.

\section{DOIS MODELOS CLÁSSICOS DE PREVIDÊNCIA SOCIAL}

O primeiro sistema de seguro social foi criado por Bismarck na Alemanha, compondo-se de três seguros compulsórios: o seguro saúde (1883), o seguro de acidentes (1884) e o seguro de velhice e invalidez (1889).

Diversos autores ${ }^{1,2,18}$ têm procurado explicar o surgimento de um sistema de proteção social tão avançado num dos países que mais tardiamente deu início ao processo de industrialização e transição do feudalismo ao capitalismo, quando outros países europeus que lideravam o desenvolvimento industrial sequer pensavam em um projeto equivalente. Estes estudos tem convergido para encontrar no próprio 
atraso da Alemanha o fundamento de sua iniciativa pioneira, e mesmo as características centrais do seguro social ali implantado. Isto porque a transição retardatária realizada pela Alemanha não se fez sob a hegemonia de uma burguesia liberal revolucionária, mas sim através de uma coalização entre as classes dominantes do velho e do novo modo de produção, construída a partir de uma decisiva intervenção do Estado na sociedade. Assim, ao invés de uma revolução burguesa, houve mais bem uma modernização conservadora, que não rompeu com o padrão de relações de autoridade tradicional.

Neste sentido, a concepção feudal na qual prepondera o binômio que troca proteção por dependência foi de certa forma preservado, só que agora a proteção social passava a ser fornecida pelo Estado.

Fica assim explicado por que o projeto do seguro social não se originou no seio da classe operária alemã, altamente politizada, mas sim na burocracia estatal, recebendo a oposição veemente do movimento operário e o apoio dos partidos conservadores. O seguro social foi assim criado como um instrumento de cooptação de setores da classe operária, de forma a diminuir o seu potencial revolucionário.

Este contexto vai imprimir uma marca fundamental no sistema do seguro social alemão que se revela na sua estrutu. ra interna e na sua doutrina. Com relação à doutrina, assume-se como filosofia central do sistema a manutenção do status econômico do indivíduo durante sua vida laboral ativa, preservando através do seguro esta mesma condição em um momento de necessidade. A operacionalização deste princípio doutrinário encontrou no modelo do seguro privado a sua melhor inspiração, já que os benefícios a serem auferidos pelo segurado são proporcionais à sua contribuição pretérita para o sistema. Além disso, os direitos sociais assim adquiridos são restritos àqueles cidadãos que, por sua inserção no mercado de trabalho, são compulsoriamente vinculados ao sistema de seguro.

Resumindo, podemos dizer que as principais características do Seguro Social são:

Quanto ao financiamento: contribuições dos empregados, dos empregadores e uma parcela menor do Estado, destinada a administração.

Quanto à administração: comitês corporativos com representação de empregados e empregadores sob o controle estatal, refletindo a concepção do Estado como árbitro no conflito entre as classes.

Quanto aos benefícios: diferenciados de acordo com a contribuição anterior, isto é, um direito contratual restrito àqueles que podem vincular-se ao sistema. 
Quanto ao regime de reservas: regime de capitalização que se baseia no conceito individual ${ }^{4}$ de formação de um capital mediante poupança para se desfrutar no futuro de suas rendas. A avaliação deste sistema se faz em termos de sua viabilidade financeira com base em técnicas atuárias e não em termos de valores socialmente definidos.

O modelo do Seguro Social apresenta alguns problemas que devem ser aqui apontados:

- O princípio doutrinário adotado, de preservação do status econômico do indivíduo, faz com que o sistema de seguro se torne um poderoso mecanismo de perpetualização das desigualdades geradas ao nível do mercado de trabalho.

- Os direitos sociais são garantidos apenas para uma parcela da classe trabalhadora que quase sempre não é a mais necessitada.

- Permite uma incorporação diferenciada das demandas sociais em função da estratificação ocupacional e da força política de cada grupo, levando quase sempre à existência de múltiplas instituições com benefícios desiguais. Os benefícios são recebidos como privilégios diferenciais e não como direitos sociais.

- Não geram um compromisso do Estado de garantir o gozo dos direitos sociais, mas sim de administrar o sistema.

- O regime de capitalização só é viável quando restringido a um grupo pequeno, no início do sistema de seguro, e quando há uma situação de estabilidade de preços. Em condições altamente inflacionárias, tende a haver uma erosão das reservas.

O segundo modelo clássico da Previdência Social originou-se na Inglaterra depois da Segunda Guerra e inspirouse no Relatório de Lord Beveridge, dando origem ao Welfare State (Estado do Bem-Estar Social). Em sua doutrina, assume a condição de cidadania como universal, independentemente, portanto, da inserção no processo produtivo ou de contribuições ao sistema, sendo dever do Estado garantir um mínimo vital aos seus cidadãos.

A Lei de Educação, a Lei do Seguro Nacional e a Lei do Serviço Nacional de Saúde, da década de 40, constituíramse nos pilares do Estado do Bem-Estar Social, cujos mecanismos básicos foram a existência de um plano de seguro contributivo, compulsório e universal; a prestação de contribuições e beneficios de valores fixos ao nivel de subsistências, e a suplementação deste mínimo por poupança voluntária ${ }^{8}$.

As reservas deste sistema de seguridade social são manipuladas pelo regime de repartição, mais adequado às segu. ridades sociais avançadas e com ampla cobertura, onde o Estado assume compromissos para o futuro em relação aos 
direitos dos beneficiários. A avaliação do sistema, neste caso, é feita em termos de projeções demográficas e econômicas de longo prazo, além dos compromissos políticos assumidos pelo Estado e que devem corresponder à sua participação decisiva no financiamento da seguridade ${ }^{4}$.

Este modelo adequar-se-ia a uma política econômica de corte Keynesiano, que supunha o pleno emprego garantido pela intervenção estatal na economia como condição da eficiência do Estado de Bem-Estar Social, ao mesmo tempo em que o próprio sistema de serviços sociais constituir-se-ia em poderoso instrumento para implementação desta poli. tica de emprego. Além da pressuposição do pleno emprego, a adoção deste modelo implicava que o Estado assumisse em grande parte os custos do sistema, já que as contribuições individuais mínimas não dariam para cobrir encargos tais como saúde e o cuidado infantil.

O Welfare State é até hoje o modelo mais avançado de Previdência Social nos países capitalistas ocidentais, e sua origem encontra explicações no fato de ser, ao contrário do caso alemão, uma conquista de uma classe operária reformista, em dois séculos de luta contra o pensamento hegemônico da burguesia liberal. Assim, quando o Partido dos Trabalhadores chegou ao governo, tratou de consolidar a cidadania como uma conquista social. Por outro lado, este momento coincidiu com uma nova etapa da produção, em bases monopolizadas, que requeria um trabalhador em condições mais hígidas. Outro fator importante foi a reformulação do estado capitalista em busca de novas estratégias legitimadoras no pós-guerra, já que tanto a proposta comunista quanto a fascista minaram as bases da solidariedade da classe trabalhadora à democracia liberal.

Independentemente do modelo adotado, se o Seguro Social ou o Welfare State, a crise econômica mundial, aliada ao envelhecimento dos sistemas, tem sido responsabilizada pela crise por que passa atualmente a previdência social européia. Esta crise é o resultado de alterações econômicas e demográficas que os responsáveis pela planificação social não poderiam antever nos tempos de prosperidade que se seguiram ao pós-guerra. Esperanças de vida mais longa fazem subir os custos dos cuidados de saúde e das pensões de velhice, enquanto que um declínio da taxa de natalidade está sobrecarregando com impostos cada vez mais elevados os trabalhadores que têm de suportar um sistema cada vez mais dispendioso. As competições comercial e industrial do Japão e Estados Unidos corroeram a prosperidade européia, sendo cada vez maior o número de desempregados que vão sobrecarregar os orçamentos do fundo de desemprego e das pensões de invalidez. 
Fica cada dia mais clara a complexa relação entre a Previdência Social e desenvolvimento, entendido não apenas como crescimento econômico, mas também pela sua orientação por uma melhor distribuição e redistribuição da riqueza social. A crise atual não se alterará enquanto as velhas indústrias européias continuarem em declínio e o desenvolvimento econômico for regredindo dia-a-dia. No entanto, os governos europeus buscam através de diversas medidas paliativas enfrentar a crise do estado-providência. Na Alemanha, o governo tem subsidiado a repatriação dos emigrantes com o objetivo de diminuir o número de dependentes do sistema previdenciário. Já o governo conservador inglês tem propalado sua intenção de cortar benefícios para diminuir os custos do sistema, sendo que, na prática, tem ocorrido o contrário, ou seja, o aumento anual do gasto público com o sistema previdenciário, que hoje representa cerca de $30 \%$ de todos os gastos públicos. Recentemente, o governo britânico divulgou um documento intitulado Green Paper, onde consolida sua proposta de reversão do Welfare State para o modelo de seguro social, em um prazo previsto de 15 anos, a ser iniciado em 1987, caso conseguisse demover a ferrenha oposição que se generalizou contra a reforma proposta.

\section{PROBLEMAS DA SEGURIDADE SOCIAL NA AMÉRICA LATINA}

Entre os técnicos de seguridade social, há muito estabeleceu-se um consenso, em grande parte decorrente da influência exercida no meio pela Organização Internacional do Trabalho, em torno da melhor forma de organização do sistema previdenciário, que estaria dado pela adoção de três conceitos centrais: universalidade, unificação e uniformidade. A universalidade refere-se ao objetivo de extensão da cobertura previdenciária a toda a população, sem distinções entre trabalhadores rurais e urbanos, engajados no mercado formal ou no informal, ou mesmo entre alguns poucos grupos de trabalhadores urbanos considerados estratégicos econômica e politicamente para o desenvolvimento do país. 0 princípio da universalidade orientaria a extensão da cobertura em um sentido horizontal, com absorção cada vez maior de novos grupos ao sistema, e não em um sentido vertical, com mais e melhores benefícios para os grupos já cobertos pelo mesmo. $O$ conceito de unificação ou centralização pressupõe tanto uma administração mais eficiente e de menor custo, quanto visa a aumentar a eqüidade interna ao sistema, já que se supõe que a unificação precede a uniformização. Neste sentido, a unificação deveria acabar com a existência de sistemas de seguros distintos por cate- 
goria ocupacional de operários ou de seguros específicos para militares, funcionários públicos etc.

Finalmente, o princípio da uniformidade reforça a noção de eqüidade, ao pressupor uma única regra a respeito das contribuições e benefícios. A operacionalização deste princípio pode ser feita de várias formas distintas, seja pelo estabelecimento de uma contribuição mínima e de um ingresso mínimo por beneficiário (caso inglês), seja pelo cálculo do benefício como uma porcentagem da contribuição pretérita de cada beneficiário (caso alemão), seja por um sistema misto, com a definição de um mínimo geral ao qual se sobreponha um adicional, calculado em proporções decrescentes, quanto maior for o correspondente ingresso ativo (método adotado na Costa Rica) ${ }^{4}$.

À simples enumeração dos três princípios centrais de previdência social moderna podemos imediatamente constatar quão distante está a América Latina do modelo ideal formulado. Alguns dos problemas centrais da seguridade social na América Latina são apontados pelos estudiosos do tema $^{6}, 12,14$ :

\section{- DESIGUALDADE NA COBERTURA}

$\mathrm{Na}$ maioria dos países do continente, as pessoas mais necessitadas, que se encontram abaixo da linha de pobreza crítica, não estão cobertas pela seguridade social, seja por que se encontrem desempregadas, subempregadas, seja por serem trabalhadores eventuais, ou que desempenhem ocupações não abrangidas pelo sistema. Segundo cálculos da CEPAL, em 1976, cerca de $35 \%$ da população da América Latina situavam-se abaixo da linha de pobreza crítica, e estima-se que, neste mesmo ano, mais de $64 \%$ da PEA não estavam cobertos pelos sistemas previdenciários.

0 esforço feito por alguns países no período mais recente, no sentido de estender a cobertura a grupos de trabalhadores anteriormente excluídos do sistema, não alcançou resultados expressivos, na medida em que os custos da filiação à previdência são tão altos relativamente à renda dos. trabalhadores inseridos na economia informal que se torna proibitivo o exercício deste direito.

Por outro lado, a distribuição desigual dos serviços, especialmente no caso da assistência médica, faz com que o segurado das regiões mais carentes custe ao sistema muitas vezes menos que um outro das regiões mais desenvolvidas.

A crise econômica acirrou drasticamente este problema, na medida em que a queda do Produto Interno Bruto da região e as medidas políticas recessivas adotadas pelos governos para enfrentarem $o$ desaquecimento da economia 
implicaram a acelerada expansão dos índices de desemprego em praticamente todos os países. As alterações no mercado de trabalho refletiram-se imediatamente sobre os níveis de proteção social, como, por exemplo, no caso do Brasil, onde, em 1976, 61,27\% dos empregados possuíam carteira de trabalho assinada - condição para o recebimento de vários benefícios - enquanto que, em 1983, este percentual caiu drasticamente para $52,78 \%{ }^{11}$.

TABELA $1^{5}$

Brasil - População trabalhadora de acordo com a contribuição para Previdência Social e categorias de renda

\begin{tabular}{|c|c|c|c|c|c|c|}
\hline \multirow{2}{*}{$\begin{array}{l}\text { Grupos de Renda } \\
\text { na Ocupação Principal } \\
\text { (Salário Mínimo) }\end{array}$} & \multicolumn{2}{|c|}{ Total } & \multicolumn{2}{|c|}{ Empregados } & \multicolumn{2}{|c|}{ Autônomos } \\
\hline & Segurado & $\begin{array}{l}\text { Não- } \\
\text { Segurado }\end{array}$ & Segurado & $\begin{array}{c}\text { Não- } \\
\text { Segurado }\end{array}$ & Segurado & $\begin{array}{c}\text { Não- } \\
\text { Segurado }\end{array}$ \\
\hline Total & 47,3 & 52,7 & 63,5 & 36,5 & 24,5 & 75,5 \\
\hline Sem Renda & 0,7 & 99,3 & - & - & - & - \\
\hline Até $1 / 2 \mathrm{SM}$ & 7,9 & 92,1 & 10,2 & 89,8 & 3,9 & 96,1 \\
\hline Mais de $1 / 2$ & & & & & & \\
\hline SM até $1 \mathrm{SM}$ & 36,7 & 63,3 & 45,7 & 54,3 & 8,9 & 91,1 \\
\hline $\begin{array}{l}\text { Mais de } 1 \text { SM } \\
\text { até } 2 \mathrm{SM} \\
\text { Mais de } 2 \mathrm{SM}\end{array}$ & 64,9 & 35,1 & 76,1 & 23,9 & 22,4 & 77,6 \\
\hline até $5 \mathrm{SM}$ & 79,6 & 20,4 & 92,3 & 7,7 & 47,5 & 42,5 \\
\hline Mais de 5 SM & 85,4 & 14,6 & 93,9 & 6,1 & 70,9 & 29,1 \\
\hline
\end{tabular}

Fonte: Tabulações especiais do IBGE, baseadas na PNAD 1977.

TABELA $2^{5}$

América Latina: PEA Segurada (1980), Gastos da Seguridade Social (1977) e Gasto Público com Saude (1977)

\begin{tabular}{lccccc}
\hline Países & PEA Segurada & $\begin{array}{c}\text { Gastos da Seguri- } \\
\text { dade Social (Excl. } \\
\text { Gastos Médicos) }\end{array}$ & $\begin{array}{c}\text { Gastos Médicos } \\
\text { da.Seguridade } \\
\text { Social }\end{array}$ & $\begin{array}{c}\text { Gasto Público } \\
\text { com Saúde }\end{array}$ & $\begin{array}{c}\text { Gasto } \\
\text { Tótal }\end{array}$ \\
\hline Argentina & 58 & 76 & 16 & 8 & 100 \\
Bolívia & 18 & 43 & 42 & 15 & 100 \\
Brasil & 47 & 78 & 21,5 & 0,5 & 100 \\
Chile & 64 & 87 & 10 & 3 & 100 \\
Colômbia & 21 & 53 & 22 & 11 & 100 \\
Costa Rica & 49 & 29 & 22 & 61 & 100 \\
El Salvador & 13 & 17 & 31 & 31 & 100 \\
Guatemala & 34 & 38 & 35 & 18 & 100 \\
Panamá & 46 & 47 & 4 & 69 & 100 \\
Uruguai & 33 & 87 & 14 & 69 \\
Venezuela & 32 & 17 & & & \\
\hline
\end{tabular}

Fonte: Baseado na OIT - "The Cost of Social Security Basic Tables", Thenth International Inquiry 1975 . 1977, Genebra, 1981. 
O problema da baixa cobertura previdenciária incide, ademais, sobre a possibilidade dos cidadãos latino-americanos terem acesso a serviços sociais, cujo gozo é responsabilidade do Estado, como no caso da proteção à saúde, já que é um fenômeno bastante generalizado a concentração dos recursos públicos para saúde quase que exclusivamente nos sistemas previdenciários, como demonstra a tabela 2:

\section{- REDISTRIBUIÇÃO DE RENDA}

Como grande parte dos sistemas previdenciários latinoamericanos são compostos de múltiplos seguros, diferenciados por categorias ocupacionais, caracteriza-se uma situação de estratificação da seguridade social $^{13}$, que se cristaliza ao nível da participação estatal em cada um dos seguros: se cada grupo houvesse financiado por si mesmo seu sistema de proteçâo, a pirâmide da seguridade social teria se limitado a reproduzir a pirâmide do ingresso. Mas os grupos mais poderosos conseguiram maiores aportes do Estado, dos empregadores, que os grupos de menor poder. Por exemplo, os militares conseguiram, èm alguns paises, que o Estado financiasse praticamente todo o sistema; os empregados públicos, que o Estado tomasse a seu cargo os déficits crescentes, e alguns profissionais ou sindicatos poderosos conseguiram que se criassem impostos especiais (sobre a produção ou serviços ligados ou não à sua atividade) que engrossaram seus fundos ${ }^{12}$.

Em 1974, os ingressos da seguridade social distribuíamse assim: (ver tabela 3 na pág. 412)

Mesmo em países com sistemas previdenciários unificados, a uniformização não é total, agravando a regressividade apontada, como no caso do Brasil, onde o Estado financia $2 / 3$ das previdências complementares das empresas estatais, com o objetivo de proporcionar um salário indireto aos seus executivos.

Além disso, a iniqüidade para com os que estão excluídos do sistema é aumentada pelo fato de que, indiretamente, todos os cidadãos contribuem para o financiamento do sistema, já que pagam impostos ao Estado e consomem produtos para cujos preços foi repassado o ônus do empregador com a previdência ${ }^{16}$. Internamente ao sistema, a concessão dos benefícios tende a aumentar a iniquidade, já que, por exemplo, as aposentadorias por tempo de serviço e por velhice só atingem a parcela mais bem aquinhoada dos trabalhadores. Perversamente, o sistema brasileiro tem como seu benefício mais democrático a aposentadoria por invalidez, que atinge amplamente os trabalhadores mais pobres e suscetíveis aos azares de um proces- 
so de desenvolvimento de cunho selvagem. Veja-se a tabela 4 a seguir:

TABELA $3^{12}$

America Latina: Distribucion Porcentual de los ingresos de seguridad social segun procedencia, 1974

\begin{tabular}{|c|c|c|c|c|c|}
\hline \multirow{2}{*}{ País } & \multicolumn{2}{|c|}{ Cotizaciones } & \multirow{2}{*}{$\begin{array}{l}\text { Contribución } \\
\text { del Estado }\end{array}$} & \multirow{2}{*}{$\begin{array}{l}\text { Renta de } \\
\text { inversiones }\end{array}$} & \multirow{2}{*}{ Otros } \\
\hline & \multicolumn{2}{|c|}{ Asegurado Empleador } & & & \\
\hline Barbados & 15.9 & 18.6 & 53.7 & 11.8 & 0.0 \\
\hline Bolivia & 17.9 & 42.8 & 32.2 & 1.5 & 5.6 \\
\hline Brasil & 36.9 & 53.9 & 5.0 & 0.1 & 3.6 \\
\hline Costa Rica & 25.2 & 45.2 & 21.7 & 6.5 & 1.4 \\
\hline Cuba & 0.0 & $0.0^{\mathrm{b}}$ & $100.0^{\mathrm{b}}$ & 0.0 & 0.0 \\
\hline Chile & 15.4 & 48.7 & 32.3 & 1.0 & 2.6 \\
\hline Ecuador & 30.2 & 32.2 & 20.4 & 16.3 & 0.9 \\
\hline El Salvador & 10.8 & 39.3 & 46.9 & 2.6 & 0.4 \\
\hline Guatemala & 23.4 & 35.2 & 39.2 & 1.3 & 1.0 \\
\hline Guyana & 20.6 & 27.7 & 39.4 & 12.3 & 0.0 \\
\hline Jamaica & 11.0 & 20.8 & 59.0 & 9.2 & 0.0 \\
\hline México & $24.0^{c}$ & $50.3^{c}$ & 19.7 & 2.5 & 3.5 \\
\hline Nicaragua & 12.9 & 31.6 & 52.4 & 2.8 & 0.3 \\
\hline Panamá & 21.2 & 45.2 & 25.2 & 6.6 & 1.8 \\
\hline Trinidad y Tabago & 12.3 & 29.5 & 54.3 & 3.9 & 0.0 \\
\hline Venezuela & 11.1 & 22.2 & 65.4 & 1.2 & 0.1 \\
\hline
\end{tabular}

Fuentes: Oficina Internacional del Trabajo, El costo de la seguridad social 1972-1974, OIT, Ginebra, 1979, pp. 43-47, 79-80, excepto Cuba de CETSS, La seguridad social en Cuba, p. 57; y Brasil de Malloy, The Politics of Social Security in Brazil, apéndice.

a Incluye un pequeño porcentaje (alrededor de $1 \%$ ) de impuestos especiales en Bolivia, Chile y Panamá; y el caso de Nicaragua un $27.9 \%$.

bas empresas (casi todas estatales) pagan un 10\% de la nómina salarial y el estado subvenciona cualquier déficit del sistema.

${ }^{c}$ En el original, las cotizaciones aparecen agregadas y fueron desagregadas por el autor basado en información adicional.

TABELA $4{ }^{15}$

Aposentadorias urbanas (médias 1979-82)

$\%$

\begin{tabular}{lccccc}
\hline \multirow{2}{*}{$\begin{array}{c}\text { Tipo de } \\
\text { Benefício }\end{array}$} & \multicolumn{2}{c}{ Participação no Total } & & \multicolumn{2}{c}{ Taxas de Crescimento } \\
\cline { 2 - 3 } \cline { 6 - 6 } \cline { 6 - 7 } & Em Número & Em Valor & & Em Número & Em Valor \\
\hline Invalidez & 50,91 & 28,82 & & 6,29 & 11,58 \\
Tempo de & & & & \\
Serviço & 31,17 & 53,43 & & 9,51 & 12,47 \\
Velhice & 13,09 & 10,52 & & 14,81 & 17,67 \\
Especial & 4,45 & 6,96 & & 10,56 & 14,17 \\
Outras & 0,38 & 0,27 & & $-9,16$ & $-7,50$ \\
Total & 100,00 & 100,00 & & 8,50 & 12,81 \\
\hline
\end{tabular}

Fonte: Tabulações DATAPREV

Caderno de Saúde Pública, R.J., 1(4): 400-417, out/dez, 1985. 


\section{- ESTADO, DESENVOLVIMENTO E PREVIDENCIA SOCIAL}

Os sistemas previdenciários latino-americanos sempre foram um dos instrumentos importantes na legitimação política dos Estados, sendo, portanto, os benefícios concedidos com objetivo de alcançar apoio político de algumas frações da classe trabalhadora. Os estudiosos do tema identificam dois fatores fundamentais na origem e evolução dos sistemas previdenciários atribuem a este fator as características mesmas do sistema: os grupos de pressão e a burocracia estatal. Aqueles que enfatizam o papel dos grupos de pressão como fator predominante na evolução de um sistema de seguridade social estratificado chamam a atenção para o fato de que quanto mais poderosos os grupos (militares, funcionários públicos, certas frações da classe operária), mais e melhores benefícios obtiveram e menor foi sua contribuição ao sistema. Neste caso, os partidos políticos e a burocracia estatal participaram da definição do modelo de proteção social, mas sempre de forma secundária à atuação dos grupos de pressão.

Outros autores enfatizam especialmente o papel do Estado em mãos de elites governamentais que, embora respondendo a pressões de grupos sociais, foram os responsáveis por oferecer uma resposta seletiva e altamente política a essas demandas. Assim, os programas de seguros sociais constituíram uma forma de acomodação corporativista de grupos sociais emergentes, particularmente dos trabalhadores nos modernos setores capitalistas da economia ${ }^{10}$.

Em qualquer das vertentes explicativas, o que se quer enfatizar é a ausência de um corpo doutrinário e de mecanismos institucionais eficientes, que reflitam o reconhecimento dos direitos sociais a partir de uma definição social da cidadania universal.

Os dois períodos mais marcantes na história das políticas previdenciárias nos países latino-americanos do cone sul estão determinados pela vigência de governos populistas e sua posterior substituição pelas ditaduras militares 20 . No caso dos regimes populistas, houve uma crescente politização das relações sociais, sendo que o mecanismo institucional previdenciário foi fundamental na cooptação de setores trabalhistas ao projeto estatal, ao mesmo tempo em que funcionaram como canal eficiente de escoamento da demanda política e social de tais grupos.

$O$ resultado deste processo foi a criação e consolidação de sistemas previdenciários fragmentados, iníquos e pouco abrangentes, embora tenha de se reconhecer que, mesmo assim, representaram um avanço significativo nas condições de vida da população trabalhadora coberta pelo sistema. 
Os governos militares autoritários também utilizaram a Previdência com vistas à sua legitimação política e maior adequação às demandas capitalistas, o que se observa na extensão da cobertura ocorrida neste período. No entanto, o uso político neste momento implicou uma desmontagem em maior ou menor grau, de acordo com a resistência encontrada - do sistema previdenciário enquanto mecanismo de realização da política populista.

Assim, os processos de centralização - com ou sem unificação - e exclusão dos beneficiários do processo decisório foram decisivos para se obter esta ruptura. A principal característica do sistema no período autoritário radica-se, no entanto, nas diversas formas de privatização do sistema previdenciário, de forma a se tornar um elemento importan. te no processo de acumulação de capitais.

O problema da relação do Estado com as reservas previdenciárias sempre foi crucial, determinando em grande parte a falência atual dos sistemas, já que, por diversas vezes, o Estado lançou mão dos fundos da Previdência (em toda América Latina) para subsidiar projetos do seu interesse e de setores do capital. Além disso, a baixa ou quase ausente contribuição estatal ao sistema sempre entrou em contradição com as necessidades políticas de legitimação de governos, através da progressiva incorporação de novos setores ao sistema ou mesmo da melhoria dos benefícios. Assim como o desenvolvimento polftico latino-americano, ao afastar-se do modelo social-democrata, imprimiu características próprias aos nossos sistemas previdenciários, também a modalidade de desenvolvimento econômico dependente, associado e retardatário, incide diretamente sobre a problemática, agravando-a, por um lado, e limitando sua possibilidade de expansão, por outro lado. O crescimento econômico na América Latina tem-se caracterizado pelo fenômeno da urbanização rápida e concentrada, acompanhada da transformação dos padrões de consumo citadinos, sob a influência dos setores de mais al ta renda, e pela incapacidade dos setores dinâmicos da economia oferecerem empregos que absorvam a população urbana, levando à formação e crescimento de camadas da população situadas de forma dita marginal, seja em relação à inserção no mercado de trabalho, seja em relação à moradia, consumo e participação política ${ }^{9}$.

Esta problemática não decorre de uma etapa do desenvolvimento, mas sim da estrutura mesma do processo de desenvolvimento dependente, cuja industrialização fez-se desde o início de forma monopolizada e com tecnologia altamente concentradora de mão-de-obra. Desta maneira, a industrialização periférica não generaliza as relações capitalistas, como ocorreu nos países centrais, mas, perversamen- 
te, recria a cada momento relações atrasadas como o artesanato, indústria caseira, o trabalho por conta própria, em estreita dependência e associação ao próprio fenômeno da industrialização.

Neste sentido, também a nossa política social terá necessariamente que diferir dos modelos desenvolvidos nos países centrais, cujo pressuposto inicial é o desenvolvimento econômico com tendência ao pleno emprego, baixo nível inflacionário, etc.

Por outro lado, o processo de industrialização levado a cabo entre nós caracterizou-se por seu caráter excludente em relação às necessidades dos trabalhadores, de tal forma que se fala do capitalismo selvagem, para indicar o desrespeito às condições mínimas de segurança do trabalho e garantia de manutenção e reprodução da força de trabalho. Este problema incide diretamente no sistema previdenciário, ao provocar um envelhecimento precoce do sistema. Os elevados índices de aposentadoria por invalidez no Brasil têm sido responsabilizados ${ }^{16}, 17$ pelo al to índice de dependência entre contribuintes e beneficiários, da ordem de 1/2,74 em 1981, o que é comparável ao envelhecimento natural dos sistemas europeus. Finalmente, outro problema freqüentemente apontado é o relativo ao financiamento da Previdência incidir basicamente sobre o fator trabalho, onerando-o de tal forma, que acabaria contribuindo, em alguma medida, para o aumento do nível de desemprego nas sociedades latino-americanas.

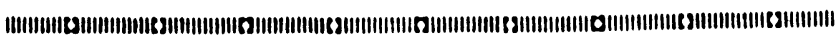

The arficle tends to approach the social political field from the citizenship development. As it is understood the roll of the rights and duties is iestablished among the citizens whose condition is confered. In this way, the author tries to show that the social politics are state's interventions conditioned by the existent necessity and from the historical context in which they arise. Thus, they can assume different forms such as the social assistance, social security and the state social welfare. The predominancy of either one of these forms in each society has shaped different models of state's intervention refering to the social questions, in more developed countries which differ according to the major or minor justice and impartiality of the social services advantageous systems. In Latin America, the development of social policies faced specific problems that are analysed by the author. 


\section{REFERENCIAS BIBLIOGRĀFICAS}

1. ABRANCHES, S. The politics of Social Welfare in Latin America. Rio de Janeiro, IUPERJ, 1982. Mimeo.

2. BENDIX, R. Estado Nacional y Ciudadania, Buenos Aires, Amorrurtu, 1978.

3. BRUNHOFF, Suzanne. Etat et Capital: recherches sur la politique économique. Paris, Maspéro, 1976.

4. DIEGUEZ, Hector. La Seguridad Social en América Latina; reflexiones sobre sus características y problemáticas, Buenos Aires, Centro de Investigaciones Económicas Instituto Torcua to Di Tella, 1977. Mimeo.

5. INSUANI, E.A. Social security and public assistance in Latin American structural limits and necessary changes. Pittsburgh, 1983. Mimeo.

6. MALLOY, J. Staticraft and insurance policy in Latin America and the United States. Pittsburgh, University of Pittsburgh, 1983. Mimeo.

7. MARSHALL, T.H. Cidadania, classe social e status. Rio de Janeiro, Zahar, 1967.

8. MARShalL, T.H. Politica social. Rio de Janeiro, Zahar, 1976.

9. MARSHALL, Wolfe. Seguridade social e desenvolvimento: a experiência latino-americana. R. Prev. Soc., (11), 1969.

10. MARTEGANI' Ariel Gionola. Nuevas estrategias para el estudo de la seguridad social. Una perspectiva teórica para el enfoque del caso uruguayo. Montevideo, Cen tro la tinoamericano de Economia Humana, 1983 (publ. n? 26).

11. MEDICI, Andre C. O mercado de trabalho brasileiro na conjun. tura recente, 1976/1983. S.1., 1984. Mimeo.

12. MESA-LAGO, Carmelo. Seguridad social y pobreza. In: SE PUEDE superar la pobreza? Santiago, CEPAL/PNUD, 1980.

13. MESA-LAGO, Carmelo. Social security in Latin America. Pressure groups, Stratification, and inequality. Pittsburgh, University of Pittsburgh, 1978. Mimeo.

14. MESA-LAGO, Carmelo \& INSUANI, E.A. La seguridad social en América Latina; problemas y recomendaciones. In: ILPES/UNICEF. Planificación social en América Latina y el Caribe. Santiago, 1981.

15. OLIVEIRA, Francisco E.B. \& AZEVEDO, M.E. Previdência Social: diagnóstico e perspectivas. $R$. Adm. publ., 19 (1): 87 , jan./mar., 1985.

16. REZENDE, F. Imprevidência da previdência. R. Econ. Pol., 4 (2) abr./jun., 1984. 
17. REZENDE. F. Redistribution of income through social security: the case of Brasil. In: CONGRESS OF INTERNATIONAL INSTITUTE OF PUBLIC FINANCE, 3a , 1974. Mimeo.

18. RIMLINGER, G. Welfare policy and industrialization in Euro. pe, America and Russia. New York, John Wiley \& Sons, 1971.

19. SANTOS, Wanderley Guilherme. Cidadania e justif̧a. Rio de Janeiro, Campus, 1979.

20. TEIXEIRA, Sonia Maria Fleury. Política social em crise na América Latina. In: SEMINÁRIO LATINO-AMERICANO DE MEDICINA SOCIAL, 3‥ Ouro Preto, 1984.

21. TEIXEIRA, Sonia Maria Fleury. Previdência versus assistência na política social brasileıra. Dados, 27 (3) : 321-45, 1984. 